\title{
Effectiveness of Non-invasive Ventilation in Treating Infants Aged 1 to 12 Months with Severe Bronchiolitis: A Systematic Review and Meta-analysis
}

\author{
Maria Lourdes C. Pagaspas, $\mathrm{MD}^{1}$ and Maria Cristina H. Lozada, MD ${ }^{1,2}$ \\ ${ }^{1}$ Department of Pediatrics, Medical Center Manila \\ ${ }^{2}$ Division of Pediatric Pulmonology, Department of Pediatrics, Philippine General Hospital, University of the Philippines Manila
}

\begin{abstract}
Objective. This study was done to determine the effectiveness of non-invasive ventilation (NIV) in treating infants aged 1 to 12 months with severe bronchiolitis based on a systematic review of literature and meta-analysis of quantitative results.

Methods. We followed the Preferred Reporting Items for Systematic Reviews and Meta-Analyses (PRISMA) flow diagram for identification, screening, and identification of eligible studies. Five databases (PubMed, Herdin, Cochrane Library, Google Scholar, and Science Direct) were searched for relevant studies involving the use of NIV among children with severe bronchiolitis. Included studies were assessed for quality and risk of bias.
\end{abstract}

Results. There were 9 included eligible studies. The length of hospital stay and duration of respiratory support were significantly lower with the use of NIV compared with IMV (invasive mechanical ventilation) based on pooled standard mean difference (SMD) estimates; however, there was high statistical heterogeneity in the included studies. This can be attributed to differences in the mode of intervention used among studies, patient-specific factors, and viral virulence. Significant improvements in heart rate, oxygen saturation, and $\mathrm{tCO}_{2}$ were seen in the included studies. One study showed statistically significant differences in changes in respiratory rate and improvement in respiratory status based on two bronchiolitis severity scores among infants placed on NIV.

Conclusion. Fair to good-quality evidence from included studies reveals that there is a significant reduction in length of hospital stay, duration of respiratory support, and improvements in respiratory parameters among infants who received NIV for severe bronchiolitis. Larger, well-designed clinical trials on the use of NIV among resource-limited settings wherein it may offer valuable clinical utility, are recommended for future study.

Keywords: non-invasive ventilation, bronchiolitis, infants, respiratory support, CPAP, BiPAP, NCPAP

\section{INTRODUCTION}

Presented and awarded $1^{\text {st }}$ Prize in the Medical Center Manila (ManilaMed) Resident's Research Presentation on December 18, 2020, at the ManilaMed, General Luna Street, Ermita, Manila, Philippines.

Presented as an Electronic Poster in the $28^{\text {th }}$ Annual (Virtual) Convention of the Philippine Infectious Disease Society of the Philippines on February 15-19, 2021.

Corresponding author: Maria Lourdes C. Pagaspas, MD Department of Pediatrics

Medical Center Manila (ManilaMed)

General Luna St., Ermita, Manila 1000, Philippines

Email: lourdespagaspas@gmail.com
The most common cause of lower respiratory tract infection among infants is bronchiolitis. ${ }^{1,2}$ This condition is commonly caused by a respiratory syncytial virus (RSV). ${ }^{3}$ The pathophysiology involves airway inflammation, edema, necrosis of epithelial cells, increased mucus production, and hypoxemia. ${ }^{4}$ This disease causes significant morbidity and mortality among infants. ${ }^{5}$

Severe bronchiolitis is the most common reason for the hospitalization of pediatric patients and may pose significant costs. $^{4,6-7}$ Furthermore, bronchiolitis leads to approximately 199,000 deaths every year in children under 5 years, with most cases occurring in developing countries. ${ }^{8,9}$ According to the Philippine Department of Health, in 2010, bronchiolitis was the third leading cause of morbidity. ${ }^{10} \mathrm{~A}$ study by 
Uenoet. al. showed that severe illness for RSV-related lower respiratory tract infections may be found in $25 \%$ of cases. ${ }^{11}$

Clinical features suggestive of severe bronchiolitis include poor feeding, tachypnea, severe chest retractions, presence of alar flaring, desaturation at room air, and lethargy; these may lead to acute respiratory failure. ${ }^{11}$ Treatment options for bronchiolitis are few. ${ }^{12}$ For more severe cases, invasive mechanical ventilation (IMV) has been widely used through an artificial airway. ${ }^{2}$ In resource-limited settings, there is an increasing need to develop safe and effective alternatives to invasive mechanical ventilation. However, presently, there are limited studies that support the use of these respiratory interventions. ${ }^{2}$

Non-invasive ventilation (NIV) refers to the application of inspiratory and expiratory pressure levels to improve minute ventilation by enhancing carbon dioxide elimination in patients with respiratory failure without an artificial airway. ${ }^{13}$ Recent studies have shown that NIV can be a beneficial alternative respiratory support for children with acute respiratory failure. ${ }^{14,15}$ Theoretically, the use of NIV in respiratory failure facilitates the recruitment of nonventilated alveoli to improve the ventilation-perfusion ratio and enhancing gas exchange. ${ }^{15}$ Studies conducted by McNamara et al., showed improvement with the use of continuous positive airway pressure as a treatment in RSV bronchiolitis. ${ }^{16}$ Moreover, studies conducted by Campio and Larrar showed a success rate of 75 to $83 \%$ with the use of NIV in bronchiolitis. ${ }^{17,18} \mathrm{NIV}$ may be administered via nasal continuous positive airway pressure (NCPAP) which uses a tight-fitting nasal mask held by head straps. ${ }^{15}$ Meanwhile, bilevel positive airway pressure (BiPAP) is another mode of NIV, wherein a higher level of inspiratory positive airway pressure is administered. ${ }^{15}$

Approximately 1-3\% of infected children may develop feeding difficulties, apnea, or are unable to maintain adequate oxygenation consistent with severe disease, which requires hospitalization. ${ }^{8,19-20}$ Infants presenting with clinical signs of exhaustion, markers of acute respiratory failure defined as the partial pressure of oxygen to fraction of inspired oxygen ratio $\left(\mathrm{PaO}_{2} / \mathrm{FiO}_{2}\right)$ of less than $300 \mathrm{mmHg}$, or signs of apnea, may require the need for assisted ventilation through mechanical ventilation. ${ }^{21,22}$ However, the use of invasive mechanical ventilation led to potential complications such as ventilator-associated pneumonia and subsequently, prolonged hospitalizations. ${ }^{23}$

Recognizing the potential complications, considerable costs, and longer hospitalization days among patients with severe bronchiolitis on mechanical ventilation, studies to explore the potential benefit of non-invasive modes of ventilation for infants with severe bronchiolitis are needed.

\section{OBJECTIVES}

Our study was done to determine the effectiveness of non-invasive ventilation in treating infants aged 1 to 12 months with severe bronchiolitis based on a systematic review of literature and meta-analysis of quantitative results. Specifically, this paper aims:

1. To determine the effectiveness of non-invasive ventilation in preventing acute respiratory failure secondary to bronchiolitis based on the following outcomes and variables: age, non-invasive ventilatory success, noninvasive ventilatory failure, development of secondary pneumonia, mortality and intubation rate, improvement in clinical parameters (heart rate, respiratory rate), and oxygenation parameters (i.e., peripheral oxygen saturation, transcutaneous $\mathrm{CO}_{2}\left[\mathrm{tCO}_{2}\right]$,

2. To determine the effectiveness of non-invasive ventilation in decreasing the length of hospital stay and duration of ventilatory support among infants with severe bronchiolitis; and,

3. To determine the safety and complications of noninvasive ventilation in severe bronchiolitis.

\section{METHODOLOGY}

\section{Study Selection}

This systematic review and meta-analysis involved randomized controlled trials, retrospective studies, and prospective observational studies on children aged 1-12 months with severe bronchiolitis and given non-invasive ventilation. We analyzed researches specifically evaluating the following modes of NIV: CPAP (continuous positive airway pressure), biPAP (bilevel positive airway pressure), and nasal NIPPV (non-invasive positive pressure ventilation). Among studies included, invasive ventilation or standard therapy using supplemental oxygen was used as a comparison to non-invasive ventilatory support.

\section{Outcomes}

The following outcomes were assessed to determine the effectiveness of NIV in infants with severe bronchiolitis:

1. Length of hospital stay(mean $\pm \mathrm{SD}$ )

2. Duration on ventilation support (mean $\pm \mathrm{SD}$ )

3. Non-invasive ventilation success (odds ratio)

4. Non-invasive ventilation failure (odds ratio)

5. Intubation rate (odds ratio)

6. Development of secondary pneumonia (n/hazard ratio)

7. Mortality(n)

8. Pediatric Risk Mortality (PRISM) scoring ${ }^{24}$

\section{Study Screening}

Studies were independently selected. There were no restrictions as to the study location and language of publication. Included studies were conducted from 2000 to 2020. Irrelevant studies which do not address the PICO (population, intervention, control or exposures, and outcomes) of our study were excluded based on the first screening of titles and abstracts. Eligibility criteria were used to evaluate the remaining full text of the articles. Disagreement in 
eligibility for inclusion was resolved by discussion between the two authors until consensus was reached.

\section{Study Selection, Information Sources, and Search Strategy}

We adhered to the PRISMA (Preferred Reporting Items for Systematic Reviews and Meta-Analyses) flow for identification, screening, and identification of eligible and included studies. ${ }^{25}$

Two investigators searched online electronic databases such as PubMed, Herdin, Cochrane Library, Google Scholar, and Science Direct for related publications. The literature search was conducted from October 13 to November 3, 2020. There were no language restrictions. The search strategy combined Medical Subject Heading $(\mathrm{MeSH})$ terms and free-text terms, including "severe bronchiolitis" and "noninvasive mechanical ventilation" or "NIPPV" or "nasal continuous positive airway ventilation" or "NCPAP" or "biPAP" or "bilevel airway pressure". A hand search was also done to look for unpublished studies (i.e, resident-in-training or fellow-in-training research papers or student theses). To avoid missing any related studies, reference lists of possible studies were checked as well. We included the following study designs: randomized controlled trials, retrospective studies, cohort studies, and prospective observational studies. Case reports, case series, and commentaries/editorials were not included in this systematic review and meta-analysis. Screening and determination of eligibility were done independently by two reviewers. In case of disagreements, it was discussed between the two reviewers until consensus was reached.

\section{Data Collection Process}

Data were extracted by two authors independently. Information on the first author, publication year, study design, study setting, number of participants, age range $($ mean $\pm S D)$, and mode of non-invasive ventilation. The following data were extracted from the included studies; age, length of hospital stay, duration of ventilatory support (mean \pm SD), non-invasive ventilatory success (odds ratio), non-invasive ventilatory success (odds ratio), intubation rate (odds ratio), development of secondary pneumonia(n/hazard ratio), mortality (n), non-invasive ventilatory failure rate using PRISM scoring.

\section{Quality Assessment and Risk of Bias Tools used in assessing individual Studies}

Study quality of non-randomized controlled trials was assessed using NIH quality assessment form. ${ }^{26}$ The Cochrane Collaboration tool, ${ }^{27}$ and Risk Of Bias In NonRandomized Studies - of Interventions (ROBINS-I) ${ }^{28}$ for assessing the risk of bias were utilized for randomized controlled trials and non-randomized controlled trials, respectively.

\section{Outcomes and Summary Measures}

After inputting data gathered from relevant eligible studies, statistical analysis and forest plot figures of pooled outcomes were generated using Review Manager software (RevMan) Version 5.3 (Copenhagen: The Nordic Cochrane Centre, The Cochrane Collaboration, 2014). ${ }^{29}$ Continuous outcome data were analyzed as mean differences (MDs). The standardized mean differences (SMD) were used to assess the association between non-invasive mechanical ventilation and the risk of respiratory failure. A random-effects model was used to calculate the pooled SMD. Dichotomous outcomes were analyzed by calculating the odds ratio (OR). Assessment of safety and harm based on the following parameters: age, length of hospital stay, duration of ventilatory support (mean $\pm \mathrm{SD})$, non-invasive ventilatory success (odds ratio), non-invasive ventilatory success (odds ratio), intubation rate (odds ratio), development of secondary pneumonia, mortality (n/hazard ratio)) and non-invasive ventilatory failure rate using PRISM scoring.

\section{Synthesis of Study Results}

Results of quantitative variables were expressed in mean with standard deviation and or percentage values. Categorical values were compared using the Mantel-Haenszel test. A $\mathrm{p}$-value of 0.05 was considered statistically significant.

\section{Additional Analyses}

The $\mathrm{I}^{2}$ statistic was used to quantify the degree of heterogeneity. An $\mathrm{I}^{2}>30 \%$ will indicate high heterogeneity. Subgroup analysis was done to determine the probability of a positive subgroup analysis (treatment subgroup interaction).

\section{Ethical Considerations}

The research proposal was submitted to the ManilaMed Ethics Research Committee (MMERC) before the commencement of this study. It was granted exemption from ethical review as there are no human participants involved and the study entailed a systematic review and meta-analysis of researches (MMERC No. 2020-17).

\section{RESULTS}

\section{Literature search and selection}

A total of 237 studies were identified from an initial exhaustive search of online electronic databases and other sources. After removing duplicates, 51 studies remained for the first screening (title and abstract screening). A total of 41 studies were subsequently retrieved for full-text review. Of the 41 studies, 9 met the eligibility criteria and were included in the qualitative synthesis. Unrelated studies that did not address the population, intervention, comparison, and outcome (PICO) questions of our review, utilized high flow nasal cannula (HFNC), compared different modes of NIV from each other (i.e,CPAP vs BiPAP), those that 
included neonates as well as non-severe bronchiolitis (moderate or mild cases of bronchiolitis) were excluded.

Our final screening revealed that 9 eligible papers underwent qualitative analysis (a total of 9 studies). ${ }^{30-38}$ Only 7 studies were included for quantitative analysis consisting of 6 retrospective studies and 1 randomized controlled trial. Figure 1 shows the PRISMA flow chart ${ }^{25}$ to illustrate the study selection process.

\section{Study Characteristics}

The characteristics of 9 included studies ${ }^{30-38}$ are presented in Table 1 . There were 6 retrospective studies ${ }^{30,32,35-38}, 2$ prospective observational studies ${ }^{31,34}$ and 1 randomized controlled trial..$^{33}$ All studies were published before October 2020, and study locations were Netherlands, ${ }^{30}$ France, ${ }^{30}$ Australia, ${ }^{32-35,37}$ India, ${ }^{33}$ Norway, ${ }^{34}$ United Kingdom, ${ }^{36}$ New Zealand ${ }^{37}$ and the United States. ${ }^{38}$ All of the included studies were in the English language. The number of participants varied across studies and ranged from 12 to 285 patients. In the included studies, ${ }^{30-38}$ a total of 1283 patients were observed to be commenced on non-invasive ventilation. The modes of non-invasive ventilation used were nasal
CPAP and biPAP. The rest of the characteristics of the included studies are shown in Table 1.

\section{Quality Assessment and Risks of Bias of Included studies}

The quality assessment was made based on the guide questions of the NIH Collaboration Tool, ${ }^{26}$ while the risk of bias for non-randomized and randomized controlled trials was assessed by utilizing the Cochrane Collaboration tool $^{27}$ and ROBINS-I. ${ }^{28}$ The included studies have addressed appropriate source population, measurement methods, study design, and statistical method.

The 8 included studies which were non-RCTs ${ }^{30-32,34-38}$ were assessed to have fair to good quality based on the NIH Collaboration Tool for quality. Using the ROBINS-I tool, on the assessment of the risk of bias, the included non$\mathrm{RCTs}^{30-32,34-38}$ were evaluated to have a low risk of bias in the following domains: bias due to confounding, participant selection, classification of interventions, deviations from intended interventions, missing data, and selection of reported results and measurements of outcomes. On the other hand, the only RCT, the study by Lal and colleagues ${ }^{33}$ was assessed

Table 1. Summary of Included Studies

\begin{tabular}{|c|c|c|c|c|}
\hline $\begin{array}{l}\text { Author, Year of } \\
\text { Publication }\end{array}$ & Type of Study & $\begin{array}{c}\text { Study Setting } \\
\text { (Location and Year) }\end{array}$ & $\begin{array}{c}\text { Participants } \\
\text { (number of patients) }\end{array}$ & Age Range (Mean) \\
\hline Borckink, 2014 ${ }^{30}$ & $\begin{array}{l}\text { Retrospective cohort } \\
\text { analysis }\end{array}$ & $\begin{array}{l}\text { Groningen, Netherlands } \\
\text { and Paris, France (January } \\
2009 \text { to February 2010) }\end{array}$ & $139(\mathrm{NCPAP}=89, \mathrm{IMV}=46)$ & $\begin{array}{l}\mathrm{NCAP}=46.5 \pm 34.8 \text { days } \\
\mathrm{IMV}=56.5 \pm 143 \text { days }\end{array}$ \\
\hline Cambonie, $2008^{31}$ & Prospective study & $\begin{array}{l}\text { Montpellier, France } \\
\text { (November } 2004 \text { to } \\
\text { March 2006) }\end{array}$ & 12 & NCAP $=46 \pm 6$ days \\
\hline Fleming, $2011^{32}$ & Retrospective analysis & $\begin{array}{l}\text { Victoria, Australia } \\
\text { (January } 2003 \text { to } \\
\text { July 2007) }\end{array}$ & 192 & Mean $=54$ days \\
\hline Lal, $2016^{33}$ & $\begin{array}{l}\text { Randomized } \\
\text { controlled trial }\end{array}$ & $\begin{array}{l}\text { Delhi, India (November } \\
2014 \text { to March 2016) }\end{array}$ & $\begin{array}{l}\mathrm{CPAP}=32 \\
\text { Standard care }=35\end{array}$ & $\begin{array}{l}\text { bCPAP }=4 \text { months } \\
\text { Standard care }=4.7 \text { months }\end{array}$ \\
\hline Oymar, $2014^{34}$ & $\begin{array}{l}\text { Prospective, obser- } \\
\text { vational (single center) }\end{array}$ & $\begin{array}{l}\text { Stavanger, Norway (May } \\
2008 \text { to April 2012) }\end{array}$ & $\begin{array}{l}\text { CPAP at ward }=33 \\
\text { CPAP at ICU }=13\end{array}$ & $\begin{array}{l}\text { CPAP at ward }=34 \text { weeks } \\
\text { CPAP at ICU }=37 \text { weeks }\end{array}$ \\
\hline Ganu, $2012^{35}$ & $\begin{array}{l}\text { Retrospective analysis } \\
\text { (single center) }\end{array}$ & $\begin{array}{l}\text { Westmead, Australia } \\
\text { (January } 2000 \text { to } \\
\text { December 2009) }\end{array}$ & $\begin{array}{l}\text { CPAP }=285 \\
\mathrm{IMV}=285\end{array}$ & Not specified \\
\hline Lazner, $2012^{36}$ & $\begin{array}{l}\text { Retrospective analysis } \\
\text { (single center) }\end{array}$ & $\begin{array}{l}\text { Sheffield, United } \\
\text { Kingdom (January } 2001 \\
\text { to February 2007) }\end{array}$ & $\begin{array}{l}\mathrm{CPAP}=61 \\
\mathrm{IMV}=6\end{array}$ & $\begin{array}{l}\text { CPAP responders }=27-40 \text { weeks } \\
\text { CPAP non-responders }=28-40 \text { weeks }\end{array}$ \\
\hline Oakley, $2017^{37}$ & $\begin{array}{l}\text { Retrospecive analysis } \\
\text { (multi-center) }\end{array}$ & $\begin{array}{l}\text { Australia and New } \\
\text { Zealand (2009 to 2011) }\end{array}$ & 204 & $\begin{array}{l}\text { Non ICU patients }=195.6 \pm 84.5 \text { days } \\
\text { ICU patients }=176.9 \pm 84.7 \text { days }\end{array}$ \\
\hline Soshnick, $2019^{38}$ & $\begin{array}{l}\text { Retrospective cohort } \\
\text { (single center) }\end{array}$ & $\begin{array}{l}\text { Connecticut, USA (2 time } \\
\text { periods: 2010-2012 and } \\
\text { 2015-2019) }\end{array}$ & $\begin{array}{l}\text { 2010-2012: } \\
\text { NCPAP = 97; BiPAP = } 4 \\
\text { 2015-2016: } \\
\text { NCPAP = 52; BiPAP = } 4\end{array}$ & Not specified \\
\hline
\end{tabular}

Abbreviations: $\mathrm{NCPAP}=$ nasal continuous positive airway pressure, biPAP = bilevel airway pressure, IMV = invasive mechanical ventilation, $\mathrm{tCO}_{2}=$ transcutaneous $\mathrm{CO}_{2}$, $\mathrm{FiO}_{2}=$ fraction of inspired oxygen 


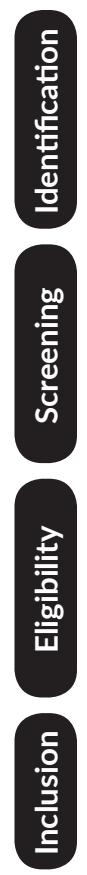

\section{Records identified through} database searching $(n=236)$

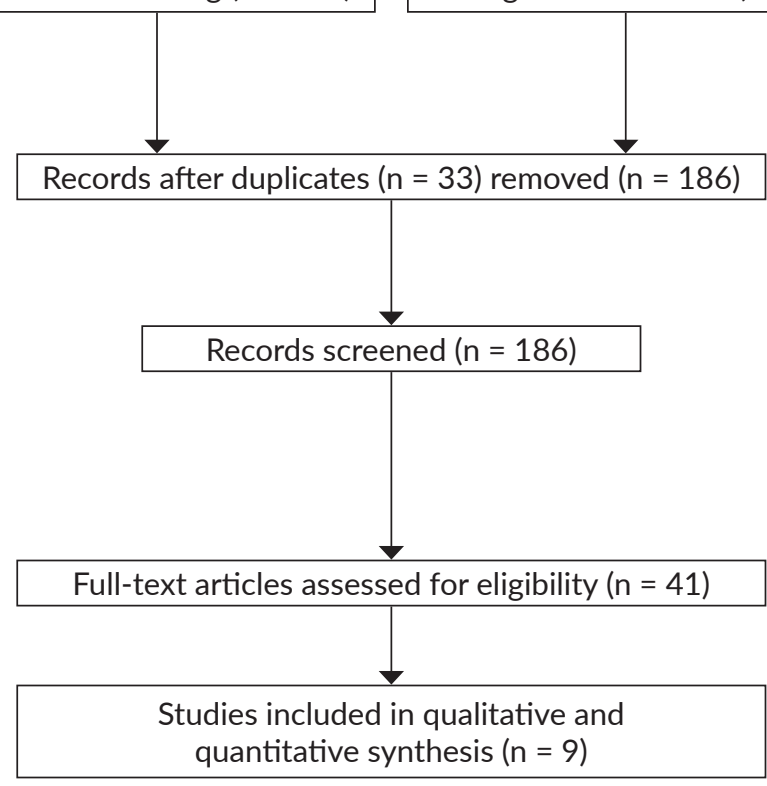

Additional records identified Additional records identified
through other sources $(n=1)$

Figure 1. The PRISMA flow diagram. ${ }^{25}$

- Pubmed $=34$

- Science Direct $=18$

- Cochrane = 47

- Google Scholar = 137

- Others = 1

Records excluded, with reasons ( $n=153$ )

- Does not answer PICO = 136

- Review articles $=9$

- Compared 2 modes of NIV with each other $=4$

- Studies conducted on neonates = 1

- Studies involving mild/moderate bronchiolitis $=3$

Full-text articles excluded, with reasons $(n=32)$

- Does not answer PICO = 11

- Compared 2 modes of NIV with each other $=1$

- Studies conducted on neonates $=4$

- Studies involving mild/moderate bronchiolitis $=1$

- Studies on HFNC = 15

\section{Males}

$\mathrm{NCAP}=47 / 89$

$\mathrm{IMV}=23 / 46$

Not reported

Invasive Mechanical NCPAP Ventilation, Supplemental oxygen, no respiratory support

bCPAP $=26 / 32$

Standard care $=28 / 35$

Oxygen via face mask or hood

BCPAP

\section{Mode of Non- Invasive Ventilation}

Main Outcomes

Other Outcomes

- Duration of respiratory support Length of PICU stay; Level and time course of $\mathrm{SpO}_{2} / \mathrm{FiO}_{2}$ ratio; Occurrence of secondary pneumonia Heart rate; $\mathrm{O}_{2}$ saturation; $\mathrm{tCO}_{2}$, mean arterial blood pressure on Modified Wood's clinical asthma score (m-WCAS)

$\mathrm{NCPAP}(6 \mathrm{~cm}$
$\mathrm{H}_{2} \mathrm{O}$ via mask)

- $\mathrm{FiO}_{2}$ requirement

$\mathrm{tCO}_{2}$, peripheral $\mathrm{O}_{2}$ saturation

- Change in respiratory rate

Need for mechanical ventilation; Silverman-Anderson score; Modified Pediatric Society of New Zealand Severity Score

CPAP at ward $=17 / 33 \quad$ None

CPAP

- Capillary $\mathrm{pCO}_{2}$ Need for mechanical ventilation

CPAP at ICU $=10 / 13$

Not specified

Invasive mechanical Nasal or full face ventilation mask CPAP

- Intubation rate

- Failure vs success of NIV

Length of hospital stay

CPAP responders Nasal prongs or vs CPAP nonNasal mask CPAP

CPAP responders

$=31 / 55$

responders vs IMV $\left(4-6 \mathrm{~cm} \mathrm{H}_{2} \mathrm{O}\right)$

$=4 / 6$

Not specified

CPAP use on ICU vs CPAP non-ICU patients

Not specified
CPAP and biPAP use Nasal CPAP and biPAP
- Ventilation days

- Peak $\mathrm{FiO}_{2}$

- Duration of $\mathrm{O}_{2}$ administration

- Place of treatment

- Total hospital days

- Length of hospital stay

- Intubation rate

- Number of intubation days

- Hospital length of stay

- ICU length of stay 
to have a low risk of bias based on the following parameters: random sequence generation, allocation concealment, blinding of participants, blinding of outcome assessment, incomplete outcome data, and selective reporting.

\section{Outcome evaluation and Meta-Analysis}

\section{Length of Hospital Stay and Duration of Ventilatory Support}

Two studies directly compared the length of hospital stay and duration of respiratory/ventilatory support among infants with severe bronchiolitis who were commenced on NIV versus invasive mechanical ventilation. ${ }^{30,31}$ Results showed that length of hospital stay is significantly lower with the use of NIV compared with invasive ventilation controls, with a pooled SMD estimate of $-1.06(95 \% \mathrm{CI}=-1.28,-0.84)$. However, there was high statistical heterogeneity between the two studies, $\mathrm{I}^{2}=99 \%$. This can be due to variability in the type of intervention used i.e. CPAP vs IMV. Also, the use of NIV also decreases the duration of ventilatory support. Using pooled SMD estimate of $-1.18(95 \% \mathrm{CI}=-1.42$, -0.95); similarly, statistical heterogeneity between studies was also noted to be high.

\section{Non-invasive ventilatory success}

Evidence supporting NIV success in the proportion of infants with severe bronchiolitis with impending respiratory failure was available. After pooling data of 6 studies, ${ }^{32,34-38}$ Odds Ratio (OR) of NIV in severe bronchiolitis was 6.44 $(95 \%$ CI $5.34,7.76)$. The odds of NIV success were six times greater among those with NIV as shown in included studies in Figure 2. There was highly significant statistical heterogeneity across studies, $I^{2}=97 \%$. This can be attributed to variation in the types of intervention being compared.

To eliminate the effect of variation in the type of intervention being used among included studies, a subgroup analysis was done. NIV success among studies, ${ }^{32,34,35}$ which utilized CPAP (Figure 3) as a treatment for severe bronchiolitis OR was 3.10 (95\%CI 2.47, 3.88). There was highly significant statistical heterogeneity across studies, $\mathrm{I}^{2}=86 \%$. This was due to the differences in patientspecific factors such as baseline apnea, refractory hypoxia, hypercarbia with acidosis, and poor general condition. In contrast, NIV success in studies utilizing NCPAP \pm / BiPAP/ NIPPV, ${ }^{36-38}$ (Figure 4) showed an OR of $86.54(95 \% \mathrm{CI}$ $52.69,142.12)$. There is no observed heterogeneity across the studies. Thus, it can be deduced that the use of NCPAP \pm / $\mathrm{BiPAP/NIPPV}$ was 86 times greater in preventing acute respiratory failure in severe bronchiolitis.

\section{Treatment failure of NIV and Escalation to Mechanical Ventilation}

Non-invasive failure in infants with severe bronchiolitis was commonly seen due to interface intolerance. ${ }^{36}$ In the study by Lal, among patients belonging to the CPAP group, 2/36 patients were escalated to mechanical ventilation compared to $1 / 36$ patients in the standard care group (supplemental oxygen only; non-CPAP). ${ }^{33}$

On the other hand, Lazner reported that there was a $10 \%$ requirement of escalating to invasive ventilation once

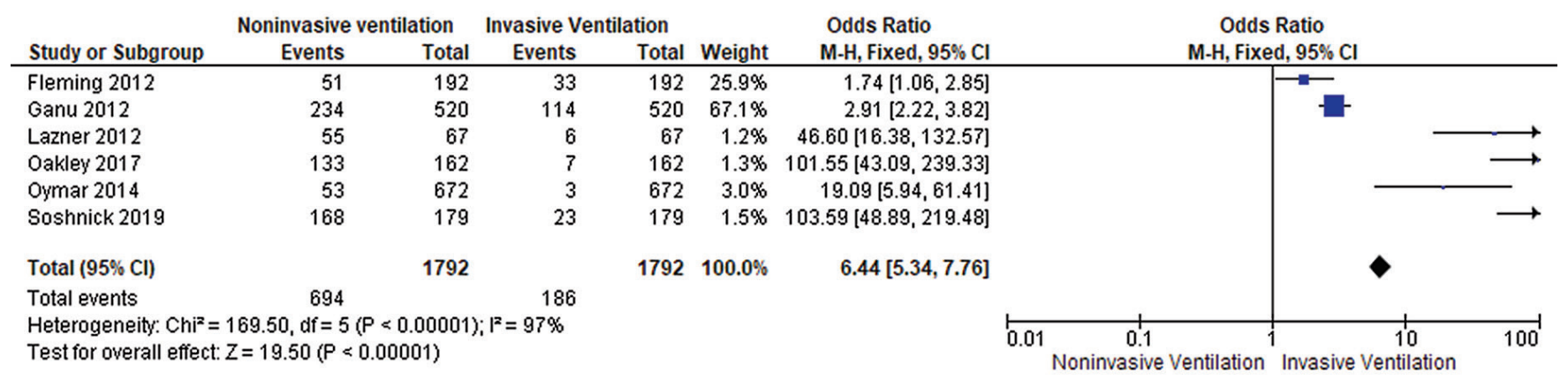

Figure 2. Forest plot of the proportion of NIV success.

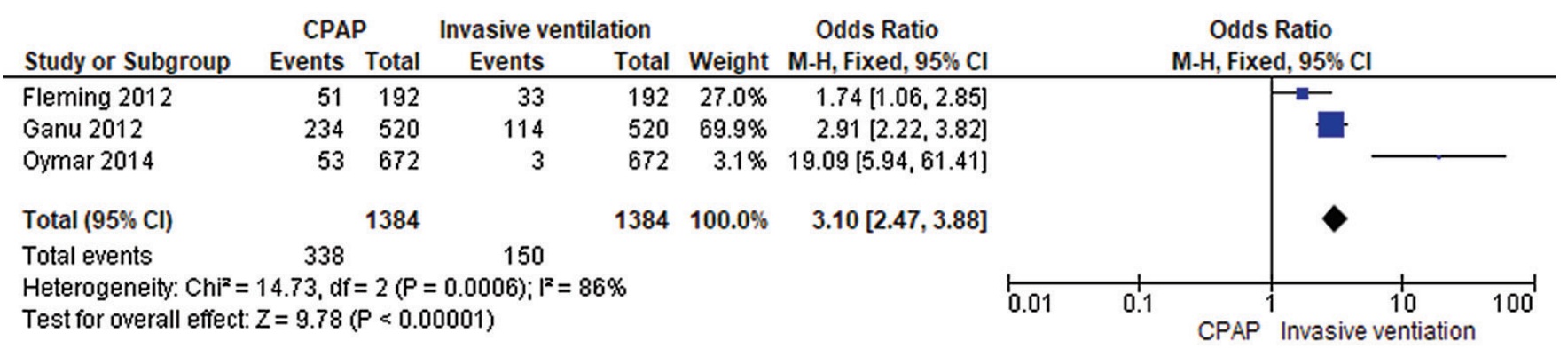

Figure 3. Forest plot of proportion of NIV success among patients placed on CPAP vs IMV. 


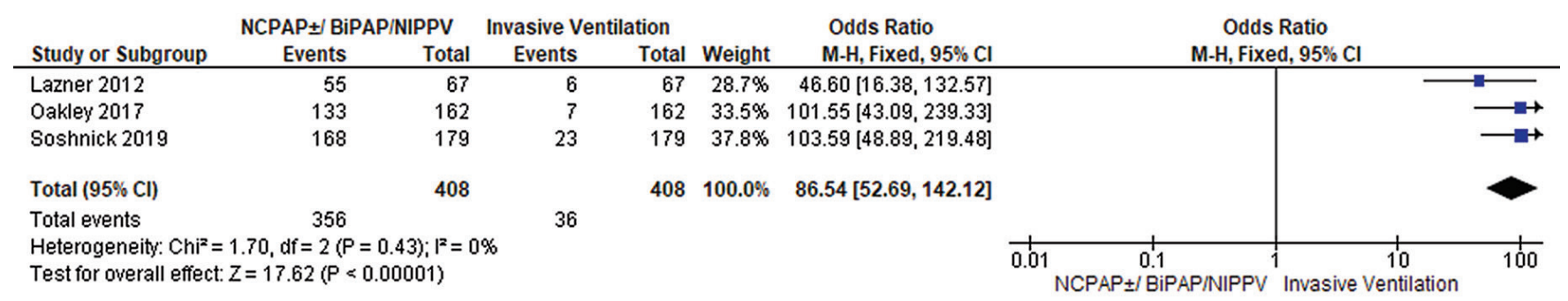

Figure 4. Forest plot of the proportion of NIV success among patients placed on NCPAP \pm / BiPAP/NIPPV vs IMV.

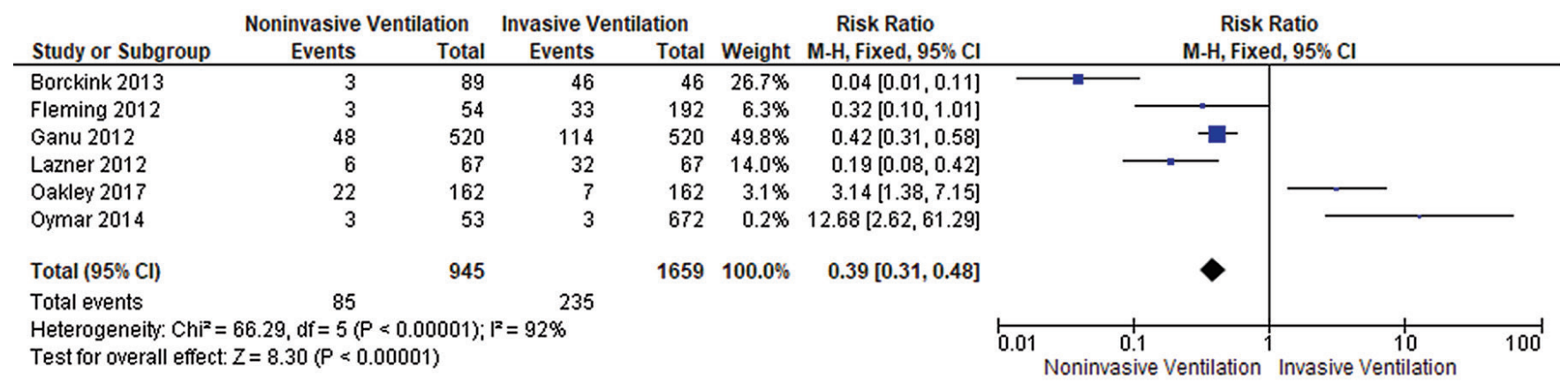

Figure 5. Forest plot of the proportion of NIV failure.

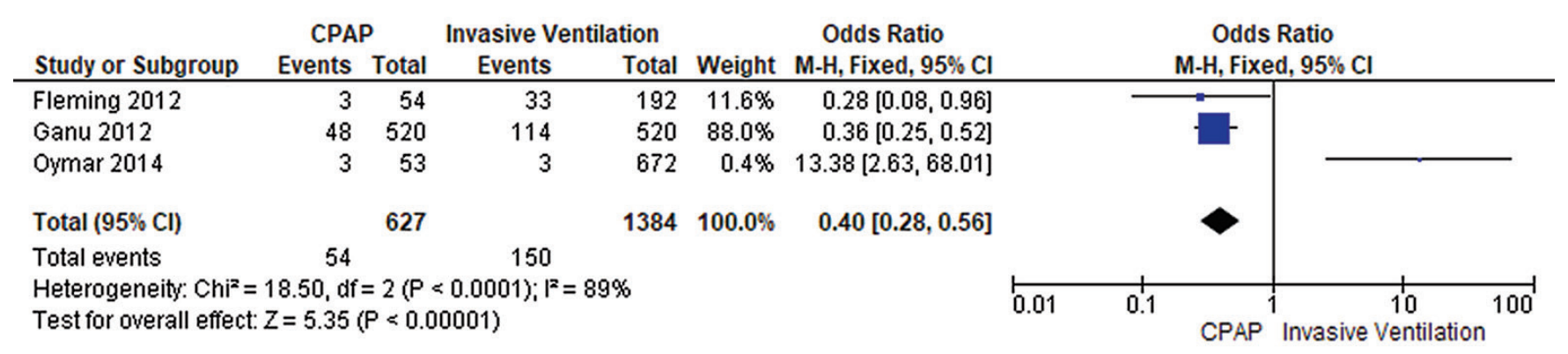

Figure 6. Forest plot of the proportion of NIV failure among CPAP vs IMV.

NIV had commenced. ${ }^{36}$ In this study, the proportion of infants with severe bronchiolitis after pooling of data showed that OR of NIV Failure was 0.39 (95\%CI 0.31, 0.48). The odds ratio of respiratory failure was lesser compared to invasive ventilation. There was highly significant statistical heterogeneity across studies, $\mathrm{I}^{2}=92 \%$ (Figure 5). This can be due to variation in treatment protocols and types of intervention among studies included.

NIV failure across studies, $32,34,35$ which utilized CPAP as a treatment for severe bronchiolitis has an OR of 0.40 (95\%CI 0.28, 0.58). In contrast, those that utilized NCPAP \pm / BiPAP/NIPPV, ${ }^{36-38}$ showed an OR of 0.26 (95\%CI 0.17 , 0.38).However, there was high significant statistical heterogeneity across studies in $\mathrm{CPAP}($ Figure 6) which may be due to the differences in patient-specific factors and viral virulence. ${ }^{34}$

\section{Changes in Clinical and Respiratory Parameters}

The RCT study by Lal et. al revealed significant differences in changes in respiratory rate (decrease in tachypnea; $\mathrm{p}$-value $=0.008)$ among patients placed in NCPAP (14/32) compared to those placed on standard care which involved supplemental oxygen via face mask (5/35). The respiratory status improvement as reflected on the Silverman-Anderson score and Modified Pediatric Society of New Zealand Severity Score for assessing bronchiolitis was also noted to be statistically significant among patients placed on CPAP. ${ }^{33}$

Furthermore, significant improvements in heart rate, respiratory rate, oxygen saturation, and $\mathrm{tCO}_{2}$ were seen in the included studies. In terms of reduction in tachycardia, a study conducted by Lazner ${ }^{36}$ showed improvement in heart rate with a mean difference of 2 beats per minute $( \pm 1.75-$ $2 \mathrm{SD})$. Also, reduction in respiratory rate there was 0.5 cycles per minute mean difference $( \pm 18-12.5$ SD), while peripheral oxygen saturation improved with a mean difference of $1 \%( \pm 1.75-2 \mathrm{SD})$. Lastly, there was noted improvement in the $\mathrm{tCO}_{2}$ mean difference of $0.6( \pm 2-6.5 \mathrm{SD}) .{ }^{36}$ 


\section{Complications}

Among the studies included, Lazner ${ }^{36}$ reported that intolerance to face masks or prong is the most common complication leading to escalation to invasive ventilation. The development of secondary pneumonia was reported in 1 participant. ${ }^{36}$ In addition, a study conducted by Borckick, ${ }^{30}$ reported an increased probability of secondary pneumonia with increased ventilatory support at a given time with a hazard ratio of 1.336 (95\%CI $0.749-2.384)$ with a p-value of 0.326 .

\section{PRISM (Pediatric Risk Mortality) and Mortality}

Treatment failure with non-invasive ventilatory has been measured in some studies using PRISM (Pediatric Risk Mortality). In which, low values of PRISM correlate with success in NIV and high values with acute respiratory failure. ${ }^{24}$ In the studies conducted by Bornick and Cambonie showed that PRISM scored showed mean of 5.1 to $8.6( \pm 1.2$ 2.8 SD). ${ }^{30-31}$ These values predict a higher success rate with NIV use. Also, the mortality rate was only reported in the study conducted by Soshnick, which showed 1 out of 179 patients treated with NIV. ${ }^{38}$

\section{Funnel Plot}

Pooled results showed high heterogeneity and included studies were assessed to have true statistical heterogeneity based on asymmetric funnel plot, as shown in Figure 7. Hence, further studies with more standardized and less heterogeneous baseline values such as baseline apnea, level of hypoxemia, and participants' general condition may be recommended.

\section{DISCUSSION}

This review yielded 9 eligible studies with a total of 1283 infants with severe bronchiolitis who received NIV via CPAP or BiPAP. Affected infants' age ranges from a mean of $46 \pm 6$

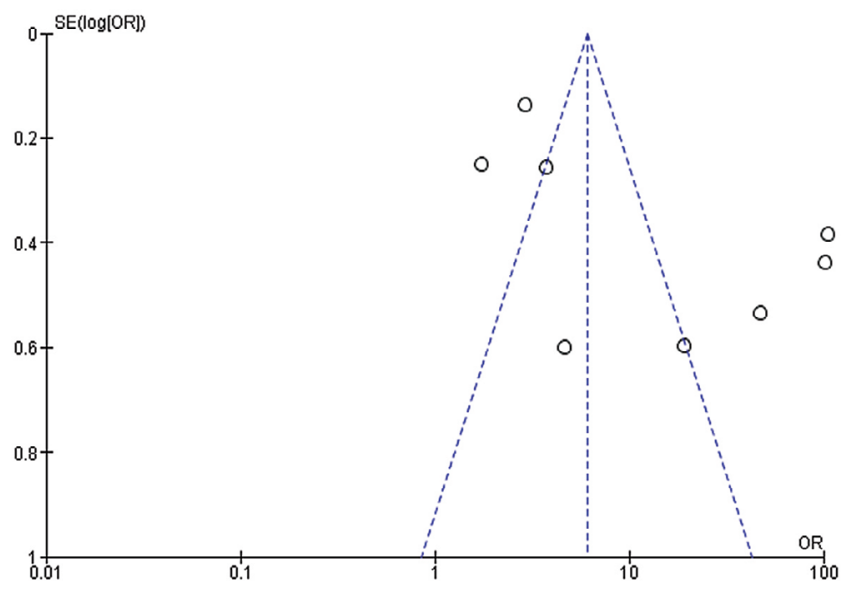

Figure 7. Funnel Plot: Noninvasive Mechanical Ventilation in Severe Bronchiolitis. days to 40 weeks. Assessment of relevant studies revealed that there is fair to good quality evidence that demonstrates that infants with severe bronchiolitis could be safely and effectively be supported by NIV. Included studies were assessed to have a low risk of bias. The length of hospital stay and duration of respiratory support is significantly lower with the use of NIV compared IMV based on pooled SMD estimates; however, there was high significant statistical heterogeneity in the included studies..$^{30-31}$ Significant improvements in heart rate, respiratory rate, oxygen saturation, and $\mathrm{tCO}_{2}$ were seen in the included studies. ${ }^{36}$ The only RCT included in this review showed statistically significant differences in changes in respiratory rate and improvement in respiratory status based on 2 bronchiolitis severity scores among children placed on NIV compared to standard therapy only. ${ }^{33}$

We observed that during the past two decades, there has been an increased use of NIV as part of the treatment of infant bronchiolitis in different areas around the world; the earliest study in the eligible papers was the one by Ganu et al., involved admitted patients in the year 2000 and was conducted in Australia. ${ }^{35}$ Soshnick et al. also reported an increase in the use of NIV in a retrospective cohort study examining the use of NIV between two time periods (20102012 and 2015-2016). ${ }^{38}$ Presently, there is no published literature on its use among children in our country. Aside from its use in the ICU setting, it may also be offered as a viable option for respiratory support among patients who are admitted at the wards, as studied in the paper by Oymar. ${ }^{34}$

Furthermore, NIV may potentially avoid risks and complications of invasive mechanical ventilation such as prolonged hospital stay, secondary bacterial infections, ventilator-associated lung injury, and oxygen toxicity secondary to exposure to high concentrations of inspired oxygen from IMV. ${ }^{33}$

Among patients with moderate severity of bronchiolitis, the study by Thia, et al. showed that young infants less than 1-year-old placed on CPAP showed statistically significant improvement in $\mathrm{pCO}_{2}$ reduction. ${ }^{39} \mathrm{CPAP}$ was noted to be well-tolerated among patients. ${ }^{39}$ Similarly, our results also showed statistically lower NIV failure rates [OR of NIV Failure was $0.39(95 \% \mathrm{CI} 0.31,0.48)]$, although there was wide heterogeneity in the included studies.

In comparison with other studies, a meta-analysis by $\mathrm{Liu}^{40}$ et al. showed that non-invasive positive pressure ventilation (NIPPV), another mode of NIV, in acute respiratory failure among adult patients showed that the use of NIV was associated with significantly reduced intubation rates. ${ }^{40}$ However, it did not have significant differences in length of ICU or hospital stay. ${ }^{40}$ This is in contrast with findings in our study, wherein we found significant reductions in the duration of hospital admission and length of respiratory support among studies that examined these parameters.

Similarly, studies conducted by Combret, ${ }^{41}$ showed that NIV reduces respiratory distress, heart rate, respiratory rate, and respiratory effort with a $\mathrm{P}<0.05$. This leads to better 
cardiorespiratory function. However, while the results of the said study noted a reduction in $\mathrm{pCO}_{2}$, the use of NIV was inconclusive in preventing endotracheal intubation. Several factors were noted to be predictive of NIV failure, particularly apnea, high $\mathrm{pCO}_{2}$, young age, low weight, elevated heart rate, and high pediatric risk mortality score. ${ }^{41}$

\section{CONCLUSIONS AND RECOMMENDATIONS}

Fair to good-quality evidence from included studies in our systematic review and meta-analysis on bronchiolitis reveals that there is a significant reduction in length of hospital stay, duration of respiratory support, improvements in heart rate, respiratory rate, oxygen saturation, and $\mathrm{tCO}_{2}$, among infants who received NIV. Larger, well-designed clinical trials in multi-center or single-center institutions, especially in resource-limited settings where NIV may offer potential benefit are recommended for future study. Other clinical variables such as intubation rate and mortality rate among children placed on NIV for severe bronchiolitis should also be included for further research.

\section{Statement of Authorship}

The final paper has been approved for submission by both authors.

\section{Author Disclosure} study.

Both authors declared no conflicts of interest in this

\section{Funding Source \\ None.}

\section{REFERENCES}

1. American Academy of Pediatrics. Subcommittee on Diagnosis and Management of Bronchiolitis Diagnosis and management of bronchiolitis. Pediatrics. 2006;118(4):1774-93.

2. Nizarali Z, Cabral M, Silvestre C, Abadesso C, Nunes P, Loureiro $\mathrm{H}$, Almeida $\mathrm{H}$. Non-invasive ventilation in acute respiratory failure from respiratory syncytial virus bronchiolitis. Rev Bras Intensiva. 2012;24(4):375-80.

3. Wagner T. Bronchiolitis. Pediatr Rev. 2009 Oct;30(10):386-95.

4. Robledo-Aceves M, Velarde-Rivera F, Esparza, EA, Preciado-Figueroa FM, Caniza MA, Escobedo-Melendez G. Risk factors for severe bronchiolitis caused by virus infections among Mexican children in an emergency department. Medicine. 2018;97:9.

5. Vicencio AG. Susceptibility to bronchiolitis in infants. Curr Opin Pediatr. 2010;22:302-6.

6. Carroll KN, Gebretsadik T, Griffin MR, Wu P, Dupont WD, Mitchel $\mathrm{EF}$, et al. Increasing burden and risk factors for bronchiolitis-related medical visits in infants enrolled in a state health care insurance plan. Pediatrics. 2008;122:58-64.

7. Caballero MT, Polack F, Stein R. Viral bronchiolitis in young infants: new perspectives for management and treatment. J Pediatr (Rio J). 2017;93(s1):75-83.

8. Oymar K, Skjerven HO, MikalsenIB. Acute bronchiolitis in infants, a review. Scandinavian Journal of Trauma, Resuscitation and Emergency Medicine, 2014;22:23.

9. Silver A, Nazif J. Bronchiolitis. Pediatrics in review. 2019;40;568.
10. Department of Health, Leading causes of Morbidity [Internet]. 2020 [cited $2021 \mathrm{Feb}$. Available from: https://www.doh.gov.ph/Statistics/ Leading-Causes-of-Morbidity.

11. Ueno F, Tamaki R, Saito M,Okamato M, Saito-Obata M,Kamigaki $\mathrm{T}$, et al. Working Group in the Philippines: Age-specific incidence rates and risk factors for respiratory syncytial virus-associated lower respiratory tract illness in cohort children under 5 years old in the Philippines. Influenza Other Respiratory Viruses. 2019;13:339-53.

12. Davison C, Ventre KM, Luchetti M, Randolph A. Efficacy of interventions for bronchiolitis in critically ill infants: a systematic review and metaanalysis. Pediatr Crit Care Med. 2004;5(5):482-9.

13. Corneli HM, Zorc JJ, Majahan P, Shaw K, Hulobkob R, Reeves S, et al. Bronchiolitis Study Group of the Pediatric Emergency Care Applied Research Network (PECARN). A multicenter, randomized, controlled trial of dexamethasone for bronchiolitis. N Engl J Med. 2007;357(4):331-9.

14. Akingbola OA, Servant GM, Custer JR, Palmisano JM. Non-invasive bilevel positive pressure ventilation: management of two pediatric patients. Respir Care. 1993;38:1092-8.

15. Thill PJ, McGuire JK, Baden HP, Green T, Checcia P. Non-invasive positive-pressure ventilation in children with lower airway obstruction. Pediatr Crit Care Med. 2002;5(4):337-42. Erratum in Pediatr Crit Care Med. 2004;5(6):590.

16. McNamara F, Sullivan CE. Nasal CPAP treatment in an infant with respiratory syncytial virus-associated apnea. Pediatr Pulmonol. 1997;24(3):218-21.

17. Campion A, Huvenne $\mathrm{H}$, Leteurtre $\mathrm{S}$, Noizet $\mathrm{O}$, Binoche A, Diependaele JF. Non-invasive ventilation in infants with severe infection presumably due to respiratory syncytial virus: feasibility and failure criteria. Arch Pediatr.2006;13:1404-9

18. Larrar S, Essouri S, Durand P, Chevret L, Haas V, Chabernaud JL, Leyronnas D, Effects of nasal continuous positive airway pressure ventilation in infants with severe acute bronchiolitis. Arch Pediatr. 2016;13:1397-1403.

19. Geoghegan S, Erviti A, Caballero MT, Vallone F, ZanoneSM et al. Mortality due to respiratory syncytial virus. Burden and risk factors. Am J Respir Crit Care Med. 2017;195:96-103.

20. Spanish Ministry for Health and Social Policy, Clinical Practice Guidelines in the Spanish National Healthcare System: Clinical Practice Guideline on Acute Bronchiolitis [Internet]. 2019 [cited 2021 Feb]. Available from: https://portal.guiasalud.es/wp-content/ uploads/2019/01/GPC_475_Bronchiolitis_AIAQS_compl_en.pdf.

21. Lopez-Fernandez Y, Azagra AM, de la Oliva P, Modesto V, Sánchez JI, Parrilla J, et al. Pediatric Acute Lung Injury Epidemiology and Natural History study: incidence and outcome of the acute respiratory distress syndrome in children. Crit Care Med. 2012;40:3238-45

22. Javouhey E, Barats A, Richard N, Stamm D, Floret D, Non-invasive ventilation as primary ventilatory support for infants with severe bronchiolitis. Intensive Care Med. 2008;34:1608-14.

23. Fedor, K. Non-invasive Respiratory Support in Infants and Children. Respir Care. 2017;62(6):699-717.

24. MuktharFR, Faizal M, Herath HM, Bamunuarachchi C, Samarasingh PT. A study on the prediction of illness related mortality of critically ill children by applying pediatric risk mortality III score in pediatric medical intensive café unit patients. Sri Lanka Journal of Child Health. 2018; 47(2): 118-24

25. Moher D, Liberati A, Tetzlaff J, Altman DG, The PRISMA Group. Preferred Reporting Items for Systematic Reviews and Meta-Analyses: The PRISMA Statement. PLoS Med. 2009; 6(7): e1000097.

26. National Institute of Health, Study Quality Assessment Tools [Internet]. 2020 [cited $2021 \mathrm{Feb}$ ]. Available from: https://www.nhlbi. nih.gov/health-topics/study-quality-assessment-tools

27. Higgins JPT, Savović J, Page MJ, Elbers RG, Sterne JAC. Assessing risk of bias in a randomized trial [Internet]. 2020 [cited $2021 \mathrm{Feb}$ ]. Available from: https://training.cochrane.org/handbook/current/ chapter-08

28. Sterne JAC, Hernán MA, Reeves BC, Savović J, Berkman ND, Viswanathan M, Henry D, et al. ROBINS-I: a tool for assessing risk 
of bias in non-randomized studies of interventions. BMJ. 2016; 355; i4919; doi: 10.1136/bmj.i4919.

29. The Cochrane Collaboration, Review Manager (RevMan) Version 5.3 [Internet] 2014 [cited $2021 \mathrm{Feb}$ ]. Available from: https://training. cochrane.org/sites/training.cochrane.org/files/public/uploads/ resources/downloadable_resources/English/RevMan_5.3_User_ Guide.pdf

30. BorckinkI, Essouri S, Laurent M, Albers MJ, BurgerhofJGM, Tissières $\mathrm{P}$, Kneyber MCJ. Infants with severe respiratory syncytial virus needed less ventilator time with nasal continuous airways pressure then invasive mechanical ventilation. Acta Paediatr. 2014 Jan;103(1):81-5.

31. Cambonie G, Mile'si C, Jaber S, Amsallem F, Barbotte E, Picaud JC. Nasal continuous positive airway pressure decreases respiratory muscles overload in young infants with severe acute viral bronchiolitis. Intensive Care Med. 2008 Oct;34(10):1865-72.

32. Fleming PF, Richards S, Waterman K, Davis PF, Omar C, Kamlin F, Sokol J, Michael Stewart. Use of continuous positive airway pressure during stabilization and retrieval of infants with suspected bronchiolitis. J Paediatr Child Health. 2012 Dec;48(12):1071-5.

33. Lal SN, Kaur J, Anthwal P, Goyal K, Bahl P, Puliyel JM. Nasal Continuous Positive Airway Pressure in Bronchiolitis: A Randomized Controlled Trial. Indian Pediatr. 2018 Jan 15;55(1):27-30.

34. Oymar K, Bardsen K. Continuous positive airway pressure for bronchiolitis in a general paediatric ward; a feasibility study. BMC Pediatrics. 2014; 14:122.
35. Ganu SS, Gautam A, Wilkins B, Egan J. Increase in use of noninvasive ventilation for infants with severe bronchiolitis is associated with decline in intubation rates over a decade. Intensive Care Med. 2012 Jul;38(7):1177-83.

36. Lazner MR, Basu AP, KloninH. Non-invasive ventilation for severe bronchiolitis: analysis and evidence Pediatr Pulmonol. 2012 Sep;47(9):909-16.

37. Oakley E, Chong V, Borland M, Neutze J, Phillips N, Krieser D, Dalziel $\mathrm{S}$, et al. Intensive care unit admissions and ventilation support in infants with bronchiolitis. Emerg Med Australia. 2017 Aug; 29(4):421-8.

38. Soshnick SH, Carroll CL, Cowl AS. Increased Use of Non-invasive Ventilation Associated With Decreased Use of Invasive Devices in Children With Bronchiolitis. Crit Care Explor. 2019 Aug; 1(8): e0026.

39. Liu YJ, Zhao J and Tang H. Non-invasive ventilation in acute respiratory failure: a meta-analysis. Clinical Medicine. 2016; 16(6):514-23.

40. Thia LP, McKenzie SA, Blyth TP, Minasan CC, Lozlowska WK, Carr SB. Randomized controlled trial of nasal continuous positive airway pressure (CPAP) in bronchiolitis. Arch Dis Child. 2008; 93:45-7.

41. Combret Y,Medrinal C, Prieur G, Le Roux P. Non-invasive ventilation improves respiratory distress in children with acute viral bronchiolitis. Minerva Anestesiologica. 2017 June 8.83 (6) 624-37. 